\title{
Study on the Preparation of High Performance Concrete using Steel Slag and Iron Ore Tailings
}

\author{
Changlong Wang ${ }^{1,2,3,4,5}$, Gaofei Zhao ${ }^{2}$, Yongchao Zheng ${ }^{1 *}$, Kaifan Zhang $^{2}$, Pengfei $\mathrm{Ye}^{2}$ and Xiaowei Cui ${ }^{6}$ \\ ${ }^{1}$ State Key Laboratory of Solid Waste Reuse for Building Materials, Beijing Building Materials Academy of Science Research, Beijing \\ 100041, China \\ ${ }^{2}$ School of Civil Engineering, Hebei University of Engineering, Handan Hebei Province, 056038, China \\ ${ }^{3}$ China National Institute of Standardization, Beijing 100191, China \\ ${ }^{4}$ Jiangxi Key Laboratory of Mining Engineering, Jiangxi University of Science and Technology, Ganzhou Jiangxi Province 341000, China \\ ${ }^{5}$ Tianjin Sunenergy Sega Environmental Science \& Technology Co. Ltd, Tianjin 300000, China \\ ${ }^{6}$ Shaanxi Key Laboratory of Comprehensive Utilization of Tailings Resources, Shangluo University, Shangluo Shaanxi Province 726000 , China
}

Corresponding Author Email: anto@163.com

\begin{abstract}
For utilize the solid waste synthetically, the cascade grinding technology was used to product cementitious materials with steel slag (SS), iron ore tailings (IOT) and granulated blast furnace slag (GBFS). The effect of SS content and curing process on compressive strength of the high performance concrete (HPC) were investigated, and the hydration products, microstructure and pore size distribution of hardened paste were studied by X-ray diffraction (XRD), scanning electron microscope (SEM) and mercury intrusion method, and the hydration mechanism of cementitious materials mixed with SS was also discussed. The results show that, SS proportion has great influence on the compressive strength of HPC. The dormant period is elongated during the hydration by the addition of large amounts of SS in the cementitious materials. Steam curing can effectively stimulate the activity of SS, and improve the early strength of cementitious materials. In the middle and later age of the hardening process, the coordinated growth of the ettringite (AFt) and C-S-H gels is significant for the strength. After mixed with SS, the proportion of harm hole increase. It is one of the most important reason for strength decline of HPC.
\end{abstract}

Keywords: steel slag; iron ore tailings; high performance concrete; ettringite; pore size distribution

Received: July-10-2019, Accepted: November-29-2019, https://doi.org/10.14447/jnmes.v22i4.a07

\section{INTRODUCTION}

At present, mineral admixtures have become an essential component and functional material of the concrete technology. The use of such materials in concrete can significantly reduce the $\mathrm{CO}_{2}$ emissions of the cement industry [1-3]. As the mineral admixture, the granulated blast furnace slag (GBFS) and fly ash have been widely used in concrete [4], so that they have gradually become scarce resources in many cities.

The iron and steel metallurgy industry is the economic foundation of the country. With its continuous development, the related problems such as resource development, energy consumption and pollutant emissions have become increasingly serious. Steel slag (SS) is one of the main solid wastes in the production process of the iron and steel metallurgy industry, and its emissions are about $15-20 \%$ of crude steel output [5]. China's annual steel slag production is about 80 million tons, with a cumulative storage of about 500 million tons, while its comprehensive utilization rate is only $22 \%$. Now there are several methods for comprehensive utilization of the SS at home and abroad, e.g., the SS is used as metallurgical raw materials (sintered materials, blast furnace flux, etc.), new building materials, and the ingredients of glass-ceramics in the road engineering, environment and agriculture, etc. However, it hasn't been widely used in cement concrete. Wang et al. [6] and Sun et al. [7] found in their study that the SS should be taken as a mineral admixture, which is the most important way to achieve the efficient use of SS resources in cement concrete. Therefore, steel slag is a potential active mineral admixture.
The mineral compositions of SS include calcium aluminates calcium silicates $\left(\mathrm{C}_{2} \mathrm{~S}, \mathrm{C}_{3} \mathrm{~S}\right),\left(\mathrm{C}_{12} \mathrm{~A}_{7}, \mathrm{C}_{3} \mathrm{~A}\right)$, RO phase (CaO-MgO-MnO-FeO solid solution), calcium ferrites $\left(\mathrm{C}_{2} \mathrm{~F}, \mathrm{C}_{4} \mathrm{AF}\right)$, free $\mathrm{CaO}$, free $\mathrm{MgO}$, $\mathrm{Fe}_{3} \mathrm{O}_{4}$, and so on [8-13]. Similar to cement, Steel slag can react with water, producing $\mathrm{Ca}(\mathrm{OH}) 2$, C-S-A-H gel, C-A-H crystal, C-S-H gel, and so on [13-15]. Thus, SS is considered as a supplemental cementitious material [16-19]. At present, SS is mainly used as subgrade engineering material, engineering backfilling materials and asphalt concrete aggregate. Less than $10 \%$ of the total amount are being applied to cement concrete [20-26].

The SS has better potential activity under the excitation of flue gas desulfurization gypsum (FGDG) [27-30]. For this, based on the research on cement concrete cementitious materials, some researchers have attempted to use the SS to replace or partially replace cement for preparing cementitious materials [31].

The application of the SS with large stockpiles and wide distribution shall lead to huge environmental and economic benefits. But when the SS is used as cementitious material in concrete, its poor stability and fluctuating composition can limit the application [32]. Therefore, this paper aims to study the application of the SS as a mineral admixture in concrete, focusing on its cementitious property and hydration characteristics. For this, it first analyses the effects of the SS powder content and the curing method on the compressive strength of the high performance concrete (HPC). Then, X-ray diffraction (XRD), scanning electron microscope (SEM) and mercury intrusion method were used to study the hydration products of SS-doped cementitious materials, microstructure of the hardened cement paste, and pore size distribution. 
The hydration mechanism of cementitious materials doped with the SS was also discussed.

\section{MATERIALS AND METHODS}

\subsection{Raw materials}

The raw materials used in the test included the steel slag (SS), iron ore tailings (IOT), GBFS, cement clinker (CC), flue gas desulfurization gypsum (FGDG), and others.

(1) SS. The SS used was basic hot steaming steel slag which complies with the Chinese National Standard GB/T 20451-2006. The chemical compositions of steel are shown in Table 1. Table 1 shows that the amount of $\mathrm{CaO}$ in the SS was approximately $40.03 \%$, and the level of residual iron in the steel slag was approximately $14.81 \%$. According to the method of the basicity calculation proposed by Mason [33], the basicity of the SS used herein is 2.17 . According to the particle size distribution of the steel slag listed in Table 2, the particles within the size range of $0.3 \sim 10 \mathrm{~mm}$ accounts for $82.03 \%$ of the total, which shows that SS need crushing before grinding.

(2) IOT. Chemical composition is shown in Table 1; the content of $\mathrm{SiO}_{2}$ in the IOT reaches $72.12 \%$ (mass fraction), as the high-silicon IOT; the main mineral composition is quartz, with a small amount of hornblende, anorthite and chlorite etc. The particle size of the tailings with a mass fraction of about $40.62 \%$ is between 0.074 and $0.16 \mathrm{~mm}$; the particles with a particle size over $0.63 \mathrm{~mm}$ occupies less than $1 \%$, and those below $0.043 \mathrm{~mm}$ are $10.43 \%$.

(3) GBFS. Water-quenched GBFS with a particle size of $0.1 \sim 0.5$ $\mathrm{mm}$, and a low crystallinity, basically in glassy state. The chemical composition of GBFS is listed in Table 1.

(4) CC. The mineral phase composition of the $\mathrm{CC}$ used in the test is mainly tricalcium silicate $\left(\mathrm{C}_{3} \mathrm{~S}\right)$, dicalcium silicate $\left(\mathrm{C}_{2} \mathrm{~S}\right)$, calcium aluminate $\left(\mathrm{C}_{3} \mathrm{~A}\right)$, and calcium ferrite $\left(\mathrm{C}_{4} \mathrm{FA}\right)$. Its chemical composition is shown in Table 1.

(5) FGDG. It's from the thermal power plant; the content of $\mathrm{CaO}$ and $\mathrm{SO}_{3}$ is the most, followed by $\mathrm{SiO}_{2}, \mathrm{MgO}$, and $\mathrm{Al}_{2} \mathrm{O}_{3} ; 16 \%$ of the components have the fineness $(\geqslant 0.08 \mathrm{~mm})$. The chemical composition

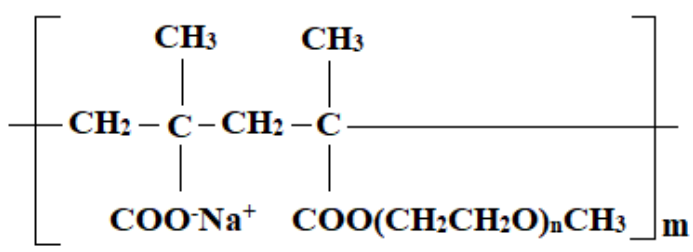

Figure 1. Molecular structure of polycarboxylic acid water-reducers

analysis is shown in Table 1.

(6) Other raw materials. The coarse aggregate stones used in the concrete preparation are limestone crushed stones with a particle size of 5 25 mm; the polycarboxylic acid (PC) superplasticizer is used, and its molecular structure is shown in Fig. 1; the test used the tap water.

\subsection{Test methods}

\subsubsection{Preparation of cementitious materials}

The cementitious material is composed of ground SS powder and basic cementitious materials (BCM). First, the mixed grinding was made in steps on the raw materials such as the IOT $(-0.074 \mathrm{~mm}$ particle size), GBFS, CC, and FGDG in a ratio of 21: 12: 12: 5 using the ball mill, following the grinding sequence in Fig. 2 to obtain the BCM. By grinding the SS separately for 90 minutes, the fine SS powder was obtained.

Then, in accordance with GB8074-87 Testing method for specific surface of cement-Blaine method, the specific surface area of the BCM and SS powder was measured to be $558 \mathrm{~m}^{2} \cdot \mathrm{kg}^{-1}$ and $624 \mathrm{~m}^{2} \cdot \mathrm{kg}^{-1}$, respectively.

It can be seen from Fig. 3 that the particle size of the BCM and SS powder were both below $10 \mu \mathrm{m}$; their D50 (median diameter) were $1.397 \mu \mathrm{m}$ and $1.962 \mu \mathrm{m}$, respectively; D90 (the corresponding particle diameter when the percentage of cumulative particle size distribution reaches $90 \%$ ) were $3.042 \mu \mathrm{m}$ and $4.649 \mu \mathrm{m}$, indicating that the raw

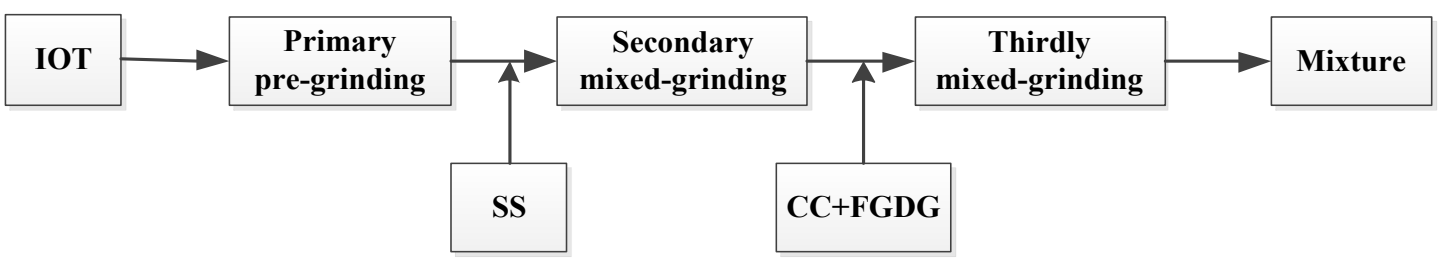

Figure 2. Flow chart of cascade grinding preparing cementitious materials [34]

Table 1. Chemical composition of raw materials (wt.\%)

\begin{tabular}{|c|c|c|c|c|c|c|c|c|c|c|c|c|}
\hline Materials & $\mathrm{SiO}_{2}$ & $\mathrm{Al}_{2} \mathrm{O}_{3}$ & $\mathrm{Fe}_{2} \mathrm{O}_{3}$ & $\mathrm{FeO}$ & $\mathrm{MgO}$ & $\mathrm{CaO}$ & f- $\mathrm{CaO}$ & f- $\mathrm{MgO}$ & $\mathrm{Na}_{2} \mathrm{O}$ & $\mathrm{K}_{2} \mathrm{O}$ & $\mathrm{SO}_{3}$ & LOI \\
\hline SS & 17.41 & 5.74 & 12.62 & 7.68 & 9.95 & 40.03 & 1.23 & 0.81 & 1.54 & 0.12 & 0.42 & 1.54 \\
\hline IOT & 72.12 & 3.04 & 12.62 & 3.44 & 1.13 & 2.96 & - & - & 0.17 & 0.14 & 0.16 & 3.06 \\
\hline GBFS & 32.70 & 15.40 & 0.40 & - & 8.97 & 38.79 & - & - & 0.02 & 0.35 & 1.93 & 0.76 \\
\hline FGDG & 3.16 & 1.35 & 0.47 & 0.09 & 7.49 & 33.38 & - & - & 0.10 & 0.24 & 45.70 & 8.28 \\
\hline $\mathrm{CC}$ & 22.50 & 4.86 & 3.43 & 0.02 & 0.83 & 66.30 & - & - & 0.11 & 0.08 & 0.31 & 0.96 \\
\hline
\end{tabular}

Table 2. The particle size distribution of SS

\begin{tabular}{|c|c|c|c|}
\hline Size $/ \mathrm{mm}$ & Individual yield $/ \%$ & Positive cumulative yield $/ \%$ & Negative cumulative yield $/ \%$ \\
\hline+10 & 4.23 & 4.23 & 100.00 \\
\hline $10 \sim 4.75$ & 30.09 & 34.32 & 95.77 \\
\hline $4.75 \sim 2.36$ & 23.47 & 57.79 & 66.68 \\
\hline $2.36 \sim 1.18$ & 16.78 & 74.57 & 42.21 \\
\hline $1.18 \sim 0.6$ & 11.98 & 86.55 & 25.43 \\
\hline $0.6 \sim 0.3$ & 8.44 & 94.99 & 13.45 \\
\hline-0.3 & 5.01 & 100.00 & 5.01 \\
\hline Total & 100.00 & - & - \\
\hline
\end{tabular}




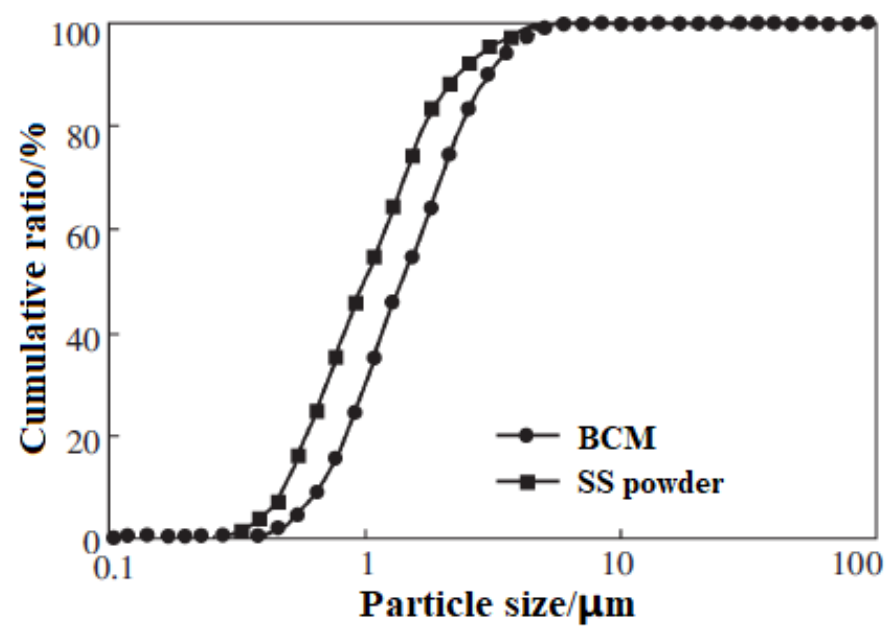

Figure 3. Particle size distribution curve of BCM and SS powder

materials after grinding contains a large number of micron and submicron particles.

(1) Test of the SS powder content

Use the ground SS powder to replace the $\mathrm{BCM}$ according to the mass fraction of $0 \%, 10 \%, 20 \%, 30 \%$, etc., and record them as $\mathrm{A} 1, \mathrm{~A} 2, \mathrm{~A} 3$, and $\mathrm{A} 4$ respectively. Table 3 lists the cementitious materials with different content of the SS. A $100 \mathrm{~mm} \times 100 \mathrm{~mm} \times 100 \mathrm{~mm}$ concrete test block was prepared at the cement-sand ratio of 1:1 (aggregate: +0.074 $\mathrm{mm}$ IOT, the same below), and the water-cement ratio of 0.23 by mixing $0.4 \%$ of the cementitious material with water reducing agent under the standard curing at the temperature $(20 \pm 1){ }^{\circ} \mathrm{C}$ and relative humidity above $90 \%$. Within the specified curing age, the test of the mechanical properties was conducted according to GB/T50081-2002 Standard for test method of mechanical properties on ordinary concrete, to determine the optimal content of the SS powder.

(2) Test of curing method

First prepare the cementitious material according to the optimal content of SS powder obtained in test (1) above. Then, prepare the 100 $\mathrm{mm} \times 100 \mathrm{~mm} \times 100 \mathrm{~mm}$ as above in test (1) for standard curing. After 1 day, the mould was disassembled and subjected to $20^{\circ} \mathrm{C}$ standard curing, $56{ }^{\circ} \mathrm{C}$ wet-heat curing, and $90{ }^{\circ} \mathrm{C}$ wet-heat curing. The three groups of samples were marked as B1 $\left(20^{\circ} \mathrm{C}\right), \mathrm{B} 2\left(56{ }^{\circ} \mathrm{C}\right)$, and B3 $\left(90{ }^{\circ} \mathrm{C}\right)$. After wet-heat curing for 12 hours, B2 and B3 were de-moulded with B1 for the standard curing. Finally, the strength test was conducted of each test block to determine the optimal curing method.

(3) Microscopic analysis for the hydration process of the cementitious materials

Prepare the cementitious materials as shown in test in (1), and then use the optimal curing method obtained in test (2) to cure the test blocks. The micro-morphology of the test blocks was finally analysed.

\subsubsection{Performance characterization}

The MASTER SIZER 2000 laser particle size analyser (test range: $0.02 \sim 2000.00 \mu \mathrm{m}$ ) was used to perform the particle size analysis of the ground material, with the ethanol as the dispersant, and the test on par-

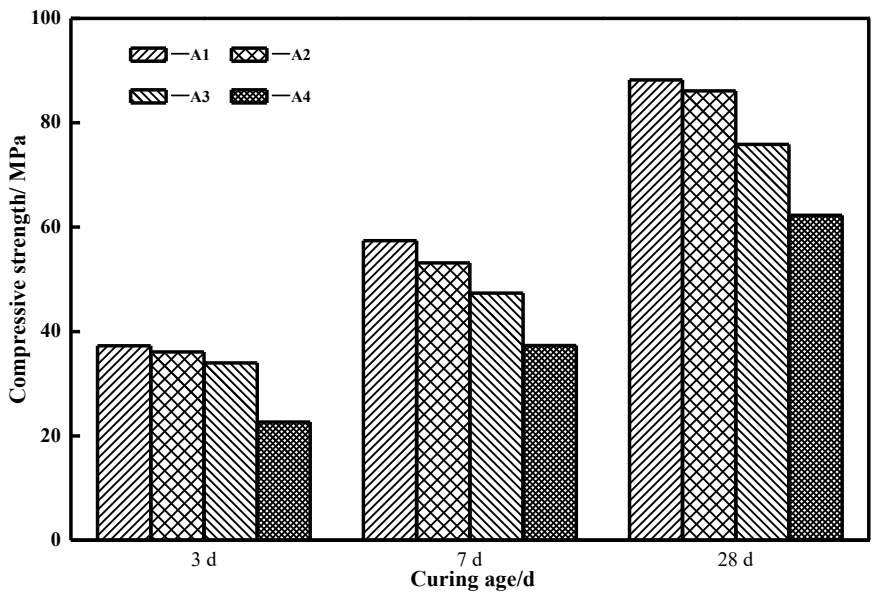

Figure 4. Effect of SS powder proportion on compressive strength of HPC

ticle size distribution of the powder was carried out with reference to GB/T19077.1-2008 Particle Size Analysis-Laser Diffraction Method. The SSA-3200 dynamic specific surface area analyser was adopted to measure the specific surface area of the ground material. The ball mill (SMФ500 mm $\times 500 \mathrm{~mm}, 5 \mathrm{~kg}$ ) was used for grinding of each material and steel. The cement paste mixer (NJ160A type), cement mortar mixer (JJ-5 type), and cement mortar fluidity tester (NLD-3 type) were applied in the cement paste and mortar of cementing materials. A singlehorizontal test chamber concrete mixer (HJW-60 type) was used for the concrete test. The compressive strength test used a digital display pressure tester (YES-300). The test piece was cured by a standard constant temperature and humidity curing box (YH-40B).

$\mathrm{X}$-ray diffraction (XRD) analysis was performed using Rigaku $\mathrm{D} / \mathrm{MAX}-\mathrm{RC} 12 \mathrm{KW}$ rotating anode diffractometer. The microstructure of the samples was analysed using ZEISS SUPTRM55 field emission scanning electron microscope (FE-SEM).

\section{RESULTS AND DISCUSSION}

\subsection{Effect of the SS content on the compressive strength of HPC}

When the SS replaces cement as a cementitious material by blending into the HPC system, it will have a great impact on the mechanical properties of concrete. Fig. 4 shows the effect of the SS content on the compressive strength of concrete under standard curing conditions.

It can be seen from Fig. 4 that with the increasing of SS powder content, the compressive strength of concrete at the curing ages of $3 \mathrm{~d}, 7 \mathrm{~d}$, and $28 \mathrm{~d}$ showed a downward trend; the 28-day compressive strength of concrete with SS powder content of $0 \%, 10 \%, 20 \%$ and $30 \%$ was 88.23MPa, 86.12MPa, 75.85 MPa and 62.26 MPa, respectively. Although all these meet the requirements of C60 concrete strength, the admixture of SS powder has a more significant impact on the compressive strength of concrete, especially on early strength.

Along with the amount of SS powder increasing from $0 \%$ to $20 \%$, the strength of concrete at all curing ages decreased, but slightly. When

Table 3. Chemical composition of cementitious materials (wt.\%)

\begin{tabular}{|c|c|c|c|c|c|c|c|}
\hline \multirow{2}{*}{ Number } & \multirow{2}{*}{$\mathrm{SS} / \%$} & \multirow{2}{*}{$\mathrm{BCM} / \%$} & \multicolumn{5}{|c|}{ Actual proportion of each raw material / \% } \\
\hline & & & SS & IOT & GBFS & $\mathrm{CC}$ & FGDG \\
\hline A1 & 0 & 100 & 0 & 40 & 26 & 26 & 8 \\
\hline $\mathrm{A} 2$ & 10 & 90 & 10 & 36 & 23.4 & 23.4 & 7.2 \\
\hline A3 & 20 & 80 & 20 & 32 & 20.8 & 20.8 & 6.4 \\
\hline A4 & 30 & 70 & 30 & 28 & 18.2 & 18.2 & 5.6 \\
\hline
\end{tabular}




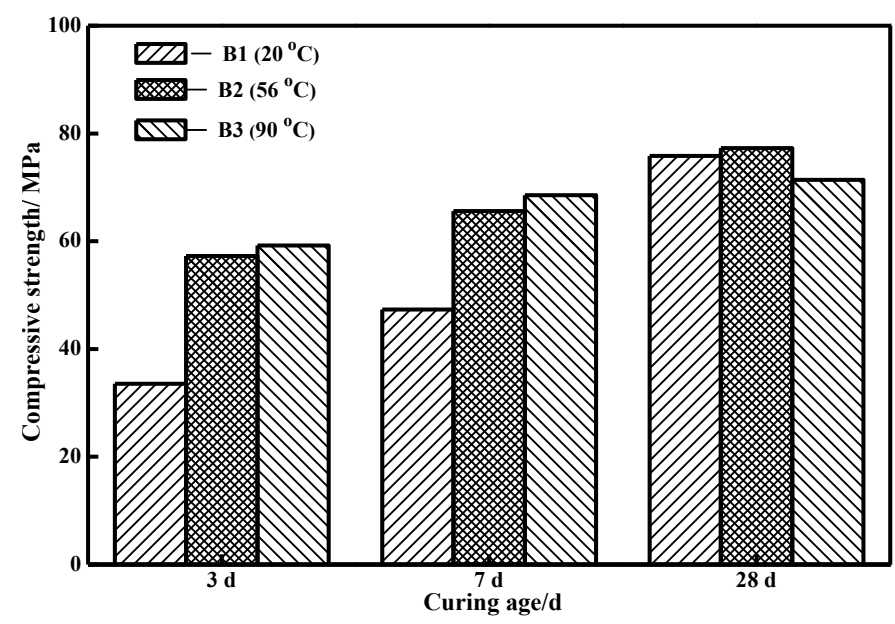

Figure 5. Effect of curing temperature on compressive strength of HPC

the amount reached $30 \%$, the compressive strength of concrete at $3 \mathrm{~d}, 7$ $\mathrm{d}$, and $28 \mathrm{~d}$ were significantly reduced, by $39.22 \%, 35.02 \%$, and $29.43 \%$ respectively compared with that of all ages without SS powder. At this time, the strength of concrete at $28 \mathrm{~d}$ was only 62.26 MPa, which was also significantly lower than $75.85 \mathrm{MPa}$, that of the concrete doped with $20 \%$ SS powder; also, due to the low content of alkaline activating substances in the system, the activity of most SS particles cannot be excited, resulting in incomplete hydration of the SS and low strength of the concrete. Therefore, the appropriate amount of SS pow-der in concrete is determined to be $20 \%$.

\subsection{Effect of curing process on strength of high- performance concrete}

The wet-heat curing can accelerate the hydration reaction of concrete, significantly increase the early strength of concrete, and shorten the production cycle. Currently it has been widely used in the production of prefabricated components. Fig. 5 shows the mechanical properties of concrete prepared by using cementitious materials doped with $20 \%$ SS powder under different curing methods.

It can be seen from the figure that the curing process has an important influence on the compressive strength of the HPC materials, especially on the early strength. At the age of 3 days, the compressive strength of $\mathrm{B} 2\left(56{ }^{\circ} \mathrm{C}\right.$ wet-heat curing at high temperature and humidity) and $\mathrm{B} 3\left(90^{\circ} \mathrm{C}\right.$ wet-heat curing at higher temperature and humidity) was significantly $23.68 \mathrm{MPa}$ and $25.62 \mathrm{MPa}$ higher than that of group B1 (standard curing $20{ }^{\circ} \mathrm{C}$ ), with the increase rates reaching $70.54 \%$ and $76.32 \%$. This is mainly due to the accelerated hydration reaction rate of the cementitious material under high-temperature curing conditions. The high temperature environment is conductive to the early hydration reaction of the active components $\left(\mathrm{C}_{12} \mathrm{~A}_{7}, \mathrm{C}_{2} \mathrm{~S}\right.$ and $\left.\mathrm{C}_{3} \mathrm{~S}\right)$ in the SS powder, leading to the rapid increase in the early strength of the HPC system. At $28 \mathrm{~d}$ age, the compressive strength of the three groups of samples all reached more than $70 \mathrm{MPa}$, but the increase in strength of group B3 concrete significantly slowed down at $7 \mathrm{~d}$ to $28 \mathrm{~d}$ age, and the strength at $28 \mathrm{~d}$ age was slightly lower than the B2 group, with the

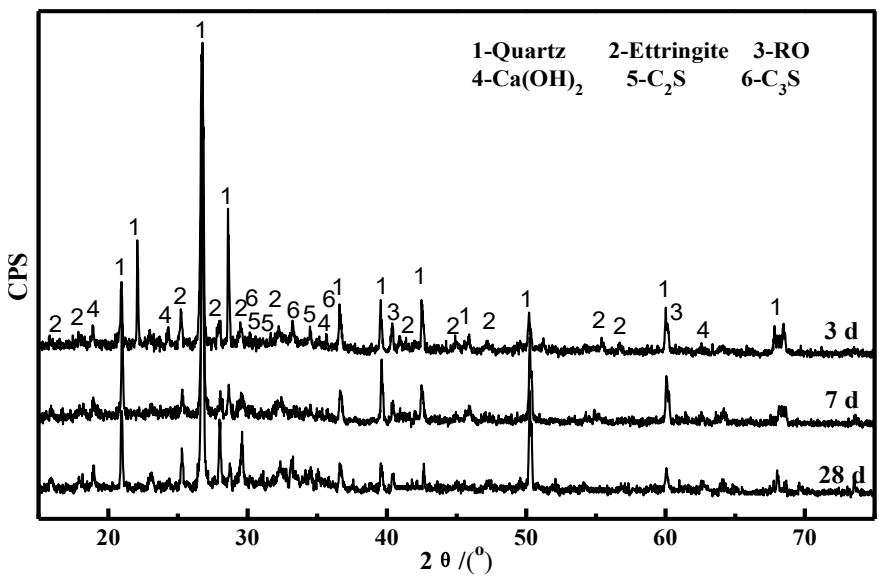

Figure 6. XRD patterns of the hydrated paste from SS at different age

micro cracks appearing on the surface of the test block at the later stage of curing. The main reason for this is that at over $70{ }^{\circ} \mathrm{C}$, ettringite dehydrated and the crystal structure was damaged; after 12 hours of wetheat curing, the standard curing at $20{ }^{\circ} \mathrm{C}$ was resumed. As a result, the ettringite could absorb water again, and showed the original structure, while the process of recrystallization was an exothermic reaction. During this process, a large amount of heat was emitted, which would expand the volume of the concrete and reduce the compressive strength of the concrete This is also the reasons why prefabricated parts rarely use high temperature curing. Therefore, a more suitable curing method for concrete doped with SS powder is to carry out the 1d standard curing after preparing the concrete test block, then demould and cure for $12 \mathrm{~h}$ under the wet-heat curing condition of $56{ }^{\circ} \mathrm{C}$, and finally perform the standard curing to the specified age.

\subsection{Pore size distribution of cementitious materials doped with SS}

The pore size distribution has an important effect on the mechanical properties and durability of the material. The mercury intrusion method was used to test the pore size distribution of the cementitious materials containing $0 \%$ and $20 \%$ SS fine powder at a hydration age of 28 days respectively. The results are shown in Table 4.

It can be seen from Table 4 that at the hydration age of 28 days, the proportion of the harmless pores (pore diameter less than $20 \mathrm{~nm}$ ) on the cementitious material mixed with $20 \%$ SS powder reached $80.53 \%$, which was slightly higher than that without SS powder, while the proportion of pore sizes in the $20 \sim 50 \mathrm{~nm}$ and $50 \sim 200 \mathrm{~nm}$ decreased slightly, and that of pore sizes over $200 \mathrm{~nm}$ increased. Also, for the two types of cementitious material, their hardened slurry test blocks contained harmful pores (pore diameter 50 200 nm) and more harmful pores (pore diameter greater than $200 \mathrm{~nm}$ ). With $20 \%$ SS powder added, the amount of more harmful pores in the cementitious material was increased and the content of harmful pores was reduced; the proportion of more harmful pores reached $9.37 \%$, which may be the reason why the strength of concrete declined with the amount of SS powder increasing.

Table 4. Pore size distribution of gelled materials cured for $28 \mathrm{~d}$

\begin{tabular}{|c|c|c|c|c|c|c|}
\hline \multirow{2}{*}{ SS content $/ \%$} & \multicolumn{4}{|c|}{ Pore size distribution / \% } & \multirow{2}{*}{ Average pore size/ nm } & \multirow{2}{*}{ Porosity / \% } \\
\hline & $>200 \mathrm{~nm}$ & $50 \sim 200 \mathrm{~nm}$ & $20 \sim 50 \mathrm{~nm}$ & $<20 \mathrm{~nm}$ & & \\
\hline 0 & 8.24 & 7.21 & 5.88 & 78.67 & 8.3 & 24.07 \\
\hline 20 & 9.37 & 5.65 & 4.45 & 80.53 & 7.8 & 21.25 \\
\hline
\end{tabular}



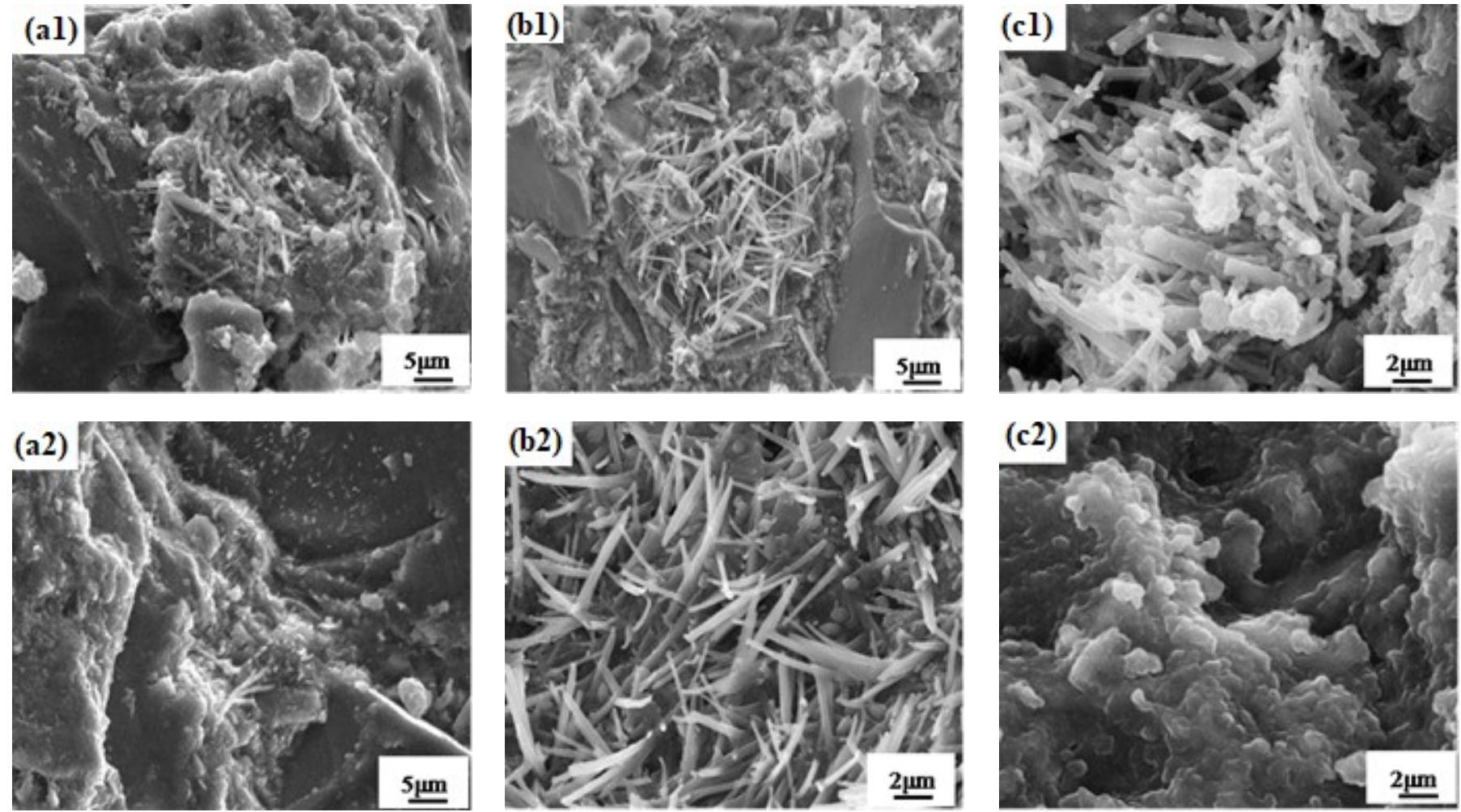

Figure 7. SEM images of the hydrated pastes from SS at different age,, (a1) and (a2) cured for $3 \mathrm{~d}$; (b1) and (b2) cured for $7 \mathrm{~d}$; (c1) and (c2) cured for $28 \mathrm{~d}$

\subsection{Hydration reaction mechanism of cementitious materials doped with SS powder}

Fig. 6 shows the XRD patterns of the test paste prepared from the cementitious materials doped with $20 \%$ fine SS powder at different ages under $56{ }^{\circ} \mathrm{C}$ wet-heat curing condition.

It can be seen from Fig. 6 that the main minerals of the SS-doped cementitious material were quartz, $\mathrm{C}_{2} \mathrm{~S}$, ettringite (AFt), a small amount of $\mathrm{Ca}(\mathrm{OH})_{2}$ and RO phases (mainly solid solutions of $\mathrm{Fe}, \mathrm{Mg}$, $\mathrm{Ca}$, and $\mathrm{Mn}$ oxides). Among them, $\mathrm{SiO}_{2}$ and $\mathrm{RO}$ phases were the main phases of the IOT and SS, respectively, and they hardly participated in the hydration reaction. In the figure, there were obvious bumps from about $23^{\circ}$ to $35^{\circ}$, which indicates the formation of C-S-H gels in the system.

At the age of $3 \mathrm{~d}$, more $\mathrm{AFt}$ and a small number of $\mathrm{Ca}(\mathrm{OH})_{2}$ diffraction peaks appeared. Meanwhile, the diffraction peaks of $\mathrm{C}_{3} \mathrm{~S}$ and $\mathrm{C}_{2} \mathrm{~S}$ were relatively obvious, which is due to the insufficient reaction between the two in the SS. Besides, cement clinker and GBFS powder also contained a large amount of $\mathrm{C}_{2} \mathrm{~S}$ and $\mathrm{C}_{3} \mathrm{~S}$, which stacked and worked together so that there are rich $\mathrm{C}_{3} \mathrm{~S}$ and $\mathrm{C}_{2} \mathrm{~S}$ in the initial system of hydration reaction. But with the extension of reaction time, the activities of the two in the SS were gradually excited and reacted with $\mathrm{Ca}(\mathrm{OH})_{2}$ to form the C-S-H gels, which gradually weakens the diffraction peaks of $\mathrm{C}_{2} \mathrm{~S}$ and $\mathrm{C}_{3} \mathrm{~S}$.

At the age of $7 \mathrm{~d}$, the diffraction peaks at $2 \theta$ of $15.150^{\circ}, 28.713^{\circ}$, $32.015^{\circ}, 48.835^{\circ}$, and $56.382^{\circ}$, etc. were significantly enhanced, indicating that many C-S-H gels and AFt were generated in the system at this time. However, the intensity of the diffraction peaks became weaker at $2 \theta$ of $17.634^{\circ}, 24.381^{\circ}$, and $36.510^{\circ}$, indicating that the amount of $\mathrm{Ca}(\mathrm{OH})_{2}$ produced by the hydration reaction was continuously participating in the reaction of $\mathrm{AFt}$, and its amount also decreased accordingly.
The $56{ }^{\circ} \mathrm{C}$ wet-heat curing promoted the $\mathrm{Al}-\mathrm{O}$ and $\mathrm{Si}-\mathrm{O}$ bonds in the SS particles to break, and these broken bonds were re-bonded with the ions in the system, which contributes to the hydration reaction. Under this curing condition, $\mathrm{SiO}_{2}-\mathrm{CaO}-\mathrm{MgO}-\mathrm{H}_{2} \mathrm{O}$ coexisted. Because of the proper temperature and humidity of the system, $\mathrm{CaO}$ reacted quickly with the active $\mathrm{SiO}_{2}$ in the system and turns into the C-S-H gels, and $\mathrm{MgO}$ was combined with the remaining active $\mathrm{SiO}_{2}$ to form magnesium silicate hydrate. In addition, $\mathrm{CaO}$ and $\mathrm{MgO}$ reacted with active $\mathrm{Al}_{2} \mathrm{O}_{3}$ to form $\mathrm{C}_{-} \mathrm{A}-\mathrm{H}$ and magnesium aluminate hydrate. With the reaction age increasing, the $\mathrm{SiO}_{2}$ and $\mathrm{Al}_{2} \mathrm{O}_{3}$ content with high activity in the system gradually decreased, and the rate of transforming $\mathrm{f}-\mathrm{CaO}$ in the $\mathrm{SS}$ to $\mathrm{Ca}(\mathrm{OH})_{2}$ was gradually greater than that of $\mathrm{Ca}(\mathrm{OH})_{2}$ consumption, so at the age of $28 \mathrm{~d}, \mathrm{Ca}(\mathrm{OH})_{2}$ diffraction peaks can still be seen clearly.

Fig. 7 shows that a large number of reaction products were generated in the concrete with a hydration age of 3 days, lots of C-S-H gels and AFt crystals were intertwined with each other, and the hardened slurry network structure was basically formed, to ensure a higher strength of concrete in the early days. Part of the $\mathrm{f}-\mathrm{CaO}$ in the $\mathrm{SS}$ gradually underwent a hydration reaction to generate $\mathrm{Ca}(\mathrm{OH})_{2}$, which is a volume expansion process, and just offsets the volume shrinkage effect caused by hydration of CC [8]. It can be seen from Fig. 7(b1) and Fig. 7(b2) that, at the age of 7 days, a large amount of AFt was produced in the system, and the grain size of AFt also grew significantly; the AFt with relatively high crystallinity was further intertwined, and the C-S-H gels in the system filled the pores, making the system denser. At the hydration age of $28 \mathrm{~d}$, with the large amount of hydration products generated, the AFt crystals were completely wrapped by the gels, the pores in the system were reduced, and the structure became denser. At the beginning, the SS powder had a slow hydration rate, and only a small amount of minerals underwent hydration reactions. However, in the middle and late stages of the reaction, the $\mathrm{RO}$ phase and a small amount of f-CaO slow- 


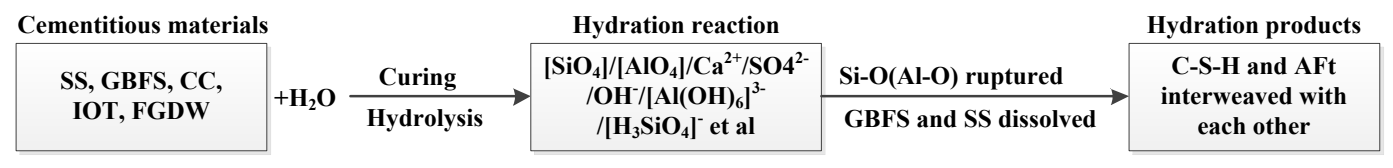

Figure 8. Schematic diagram of the hydration reaction mechanism of cementitious materials $[35,36]$

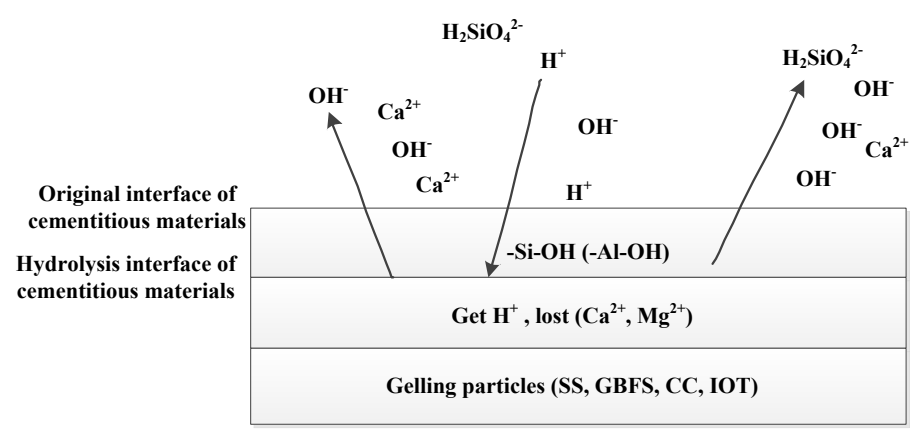

Figure 9. Hydration process model of cementitious materials [35, 36]

ly participated in the hydration reaction, and its hydration products were mainly $\mathrm{Ca}(\mathrm{OH})_{2}$, C-S-H gels. In the system, both AFt and C-S-H gels are synergistically formed, which effectively promotes the strength of the HPC.

During the mechanical grinding process, the SS, IOT, and GBFS particles were subjected to mechanical forces, and produced local lattice distortions. The lattice distortions increased the lattice energy, causing the breakage and reorganization of Si-O and Al-O chemical bonds, so that the periodic boundary conditions that originally reached equilibrium change, the long-range ordered structure of the crystal particles was destroyed, and the mineral changed from crystalline to amorphous. New defects appeared on the surface of the powder particles, and the particle activity increased, which helps the hydration process to proceed smoothly.

Fig. 8 shows a schematic diagram of the hydration reaction mechanism of cementitious materials for the HPC, and Fig. 9 shows a hydration reaction model of the SS and IOT for cementitious materials. The bonding structures of silicate and aluminate minerals in the SS were mainly silicon-oxygen bonds and aluminium-oxygen bonds. They mainly existed in the form of $\left[\mathrm{SiO}_{4}\right]$ tetrahedron, $\left[\mathrm{AlO}_{4}\right]$ tetrahedron or $\left[\mathrm{AlO}_{6}\right]$ coordination polyhedron. After encountering water, the particles with higher activity quickly dissolved under the basic environmental conditions of gypsum, and released a large amount of $\mathrm{OH}^{-}, \mathrm{Ca}^{2+}, \mathrm{Al}^{3+}$ ions, forming the liquid phase rich in ions such as $\mathrm{Ca}^{2+},\left[\mathrm{Al}(\mathrm{OH})_{6}\right]^{3-}$, $\mathrm{SO}_{4}^{2-},\left[\mathrm{H}_{3} \mathrm{SiO}_{4}\right]^{-}$, and $\mathrm{OH}^{-}$. These tetrahedral structures continued to recombine with the ions in the liquid phase, and generated relatively stable zeolite facies hydration products. As a result. the silicon-oxygen bond and aluminium-oxygen bond in the SS were constantly broken, the SS was also continuously dissolved, and the hydration products gradually filled the pores of the reticular network structure, so that the all-solid waste concrete system is gradually dense and the compressive strength also increases.

As the hydration reaction progressed, the surface of the IOT particles de-polymerized, and the depolymerized ions entered the liquid phase under the action of $\mathrm{OH}^{-}$, which supplemented the solution $\left[\mathrm{H}_{3} \mathrm{SiO}_{4}\right]^{-}$, $\left[\mathrm{H}_{3} \mathrm{AlO}_{4}\right]^{2-}$, and $\left[\mathrm{Al}(\mathrm{OH})_{6}\right]^{3-}$ ion; using the mutual excitation effect among the fine powders of the SS, GBFS, and gypsum, while forming a large number of ettringite and needle-shaped double salt crystals, it also formed many approximately amorphous C-S-H gels and zeolitelike phase, and the needle-shaped double salt crystals were tightly wrapped, greatly improving the stability of the entire concrete system.

During the hydration process, the low-iron aluminium phases (such as $\mathrm{C}_{2} \mathrm{~F}$ and $\mathrm{C}_{6} \mathrm{AF}_{2}$ ) in the $\mathrm{SS}$ also participated in the hydration reaction. The main reactions are shown in formulas (1) and (2):

$$
\begin{aligned}
& 2\left(2 \mathrm{CaO} \cdot \mathrm{Fe}_{2} \mathrm{O}_{3}\right)+4 \mathrm{H}_{2} \mathrm{O} \rightarrow \\
& \begin{array}{r}
6 \mathrm{CaO} \cdot \mathrm{Al}_{2} \mathrm{O}_{3} \cdot 2 \mathrm{Fe}_{2} \mathrm{O}_{3}+10 \mathrm{H}_{2} \mathrm{O} \rightarrow \\
3 \mathrm{CaO} \cdot \mathrm{Al}_{2} \mathrm{O}_{3} \cdot 6 \mathrm{H}_{2} \mathrm{O}+2 \mathrm{Oe}(\mathrm{OH})_{3} \cdot \mathrm{H}_{2} \mathrm{O}+2 \mathrm{Fe}(\mathrm{OH})_{3}
\end{array}
\end{aligned}
$$

Meanwhile, the divalent metal oxides $(\mathrm{CaO}+\mathrm{MgO}+\mathrm{FeO})$ in the $\mathrm{SS}$ were also the material basis for stimulating the formation of C-S-H gels with the GBFS and tailings. It reacted with $\mathrm{Al}_{2} \mathrm{O}_{3}$ and $\mathrm{Fe}_{2} \mathrm{O}_{3}$ to form AFTcontaining double salt with the participation of FGDG. The reaction is shown in formula (3):

$$
\begin{gathered}
2\left(\mathrm{Al}^{3+}, \mathrm{Fe}^{3+}\right)+3\left(\mathrm{Ca}^{2+}, \mathrm{Mg}^{2+}, \mathrm{Fe}^{2+}\right)+3\left(\mathrm{CaSO}_{4} \cdot 2 \mathrm{H}_{2} \mathrm{O}\right)+ \\
12 \mathrm{OH}^{-}+20 \mathrm{H}_{2} \mathrm{O} \\
\rightarrow 3(\mathrm{CaO}, \mathrm{MgO}, \mathrm{FeO}) \cdot\left(\mathrm{Al}_{2} \mathrm{O}_{3}, \mathrm{Fe}_{2} \mathrm{O}_{3}\right) \cdot 3 \mathrm{CaSO}_{4} \cdot 32 \mathrm{H}_{2} \mathrm{O}
\end{gathered}
$$

In addition, fine-grained SS and IOT can have a micro-aggregate effect. Many sub-micron and nano-sized particles that have not participated in the reaction are densely packed and filled in the hardened cement slurry, which reduces the porosity of the system and strengthens the overall structure of the hardened. Thus, the compressive strength of the concrete also improves accordingly.

\section{CONCLUSIONS}

(1) The admixture of SS powder has a relatively significant impact on the compressive strength of concrete, especially on its early strength. With the amount of SS powder increasing, the compressive strength of concrete at the ages of $3 \mathrm{~d}, 7 \mathrm{~d}$, and $28 \mathrm{~d}$ showed a downward trend. The appropriate amount of SS powder is determined to be $20 \%$.

(2) The curing process has a significant effect on the compressive strength of the HPC. High-temperature wet-heat curing is conducive to the improvement of early strength of concrete, but too high temperature may cause dehydration and recrystallization of ettringite, which is not good for the later stability of concrete.

(3) At the beginning, the SS powder was hydrated slowly, but in the middle and late stages of the reaction, the RO phase and a small amount of $\mathrm{f}-\mathrm{CaO}$ slowly participated in the hydration reaction. Its hydration products were mainly $\mathrm{Ca}(\mathrm{OH})_{2}$ and C-S-H gels. In the system, both AFt and C-S-H gels are synergistically formed, which effectively promotes the strength increase of the all solid waste concrete system.

(4) The incorporation of SS powder increases the proportion of more harmful pores at the hydration age of 28 days, which is one of the reasons that the strength of concrete decreases with the increase of the amount of SS.

\section{ACKNOWLEDGMENTS}

The authors gratefully acknowledge financial support from China Postdoctoral Science Foundation (2016M602082), supported by Natural Science Foundation of Hebei Province (E2018402119), supported by Natural Science Foundation of Shaanxi Province (2019JLM-49), supported by Shaanxi Science and Technology Benefit People Project 
(2018ZY-HM-01), supported by Science and Technology Research Project of Higher Education Universities in Hebei Province (ZD2016014, QN2016115), supported by Comprehensive Utilization of Tailing Resources Key Laboratory of Shaanxi Province (2017SKYWK008), supported by Jiangxi Postdoctoral Daily Fund Project (2016RC30), supported by Jiangxi Postdoctoral Research Project (2017KY19), supported by State Key Laboratory of Solid Waste Reuse for Building Materials (SWR-2019-008).

\section{REFERENCES}

[1] Wu Z. W, Lian H Z. High Performance Concrete. China Railway Publishing House, Beijing, 1999.

[2] Wang Q, Yan P Y, Yang J W., Journal of Wuhan University of Technology-Materials Science Edition, 29(2), 273 (2014).

[3] Mehta P K., Concrete International, 10(3), 18 (2001).

[4] Aïtcin P C., Cement and Concrete Research, 25(4-5), 409 (2003).

[5] Shi C J., Journal of materials in civil engineering, 36, 230 (2005).

[6] Wang Q, Yan P Y., Construction and Building Materials, 24(7), 1134 (2010).

[7] Sun J Y., Journal of Building Materials, 8(1), 63 (2005).

[8] Shi C J., Cement and Concrete Research, 32(3), 459 (2002).

[9] Kourounis S, Tsivilis S, Tsakiridis P E, Papadimitriou G D, Tsibouki G., Cement and Concrete Research, 37(6), 815 (2007).

[10]Waligora J, Bulteel D, Degrugilliers P, Damidot D, Potdevin J L, Materials Characterization, 61(1), 39 (2010).

[11]Liu S J, Hu Q Q, Zhao F Q, Chu X M., Construction and Building Materials, 72, 15 (2014).

[12]Yan P Y, Mi G D, Wang Q., Journal of Thermal Analysis and Calorimetry, 115(1), 193 (2014).

[13]Wang Q, Yang J W, Yan P Y., China Technological Sciences, 55(12), 3378 (2012).

[14]Wang Q, Yan P Y, Feng J W., Journal of Hazardous Materials, 186(2-3), 1070 (2011).

[15]Lam L, Wong Y L, Poon C S., Cement and Concrete Research, 30(5), 747 (2000).

[16]Wang S, Wang C L, Wang Q H, Liu Z Y, Qian W, Jin C Z, Chen L, Li X W, Li L., Polish Journal of Environmental Studies, 27(1), 357 (2018).

[17]Mladenovič A, Mirtič B, Meden A, Serjun V Z., Construction and Building Materials, 116, 216 (2016).

[18]Zhang G Q, Wu P C, Gao S J, Ye P F, Wang C L, Huo Z K, Zhang K F, Zhan Z N, Meng X Q., Acta Microscopica, 28(5), 961 (2019).

[19]Cui H L, Zhang K F, Zhang G Q, Wang C L, Zhan Z N, Chang N, Lin X R, Meng X Q., Acta Microscopica, 28(4), 835 (2019).

[20]Maslehuddin M, Alfarabi M, Sharif M, Ibrahim M, . Barry M S., Construction and Building Materials, 17(2), 105 (2003).

[21]Wang G., Construction and Building Materials, 24(10), 1961 (2010).

[22]Manso J M, Polanco J A, Losañez M, González M M., Cement \& Concrete Composites, 28(6), 528 (2006).

[23]Ahmedzadea P, Sengozb B., Journal of Hazardous Materials, 165(1-3), 300 (2009).

[24]Pasetto M, Baldo N., Journal of Hazardous Materials, 181 (1-3), 938 (2010).

[25]Xue Y J, Wu S P, Hou H B, Zha J., Journal of Hazardous Materials, 138(2), 261 (2006).

[26]Qasrawi H, Shalabi F, Asi I., Construction and Building Materials, 23(2), 1118 (2009).

[27]Ashrit S, Chatti R V, Udpa K N, Venugopal R, Nair U G., MOJ Mining and Metallurgy, 1(1), 1 (2017).
[28]Zhao J H, Wang D M, Yan P Y, Zhang D W, Wang H., Construction and Building Materials, 113, 835 (2016).

[29]Duan S Y, Liao H Q, Cheng F Q, Song H P, Yang H Q., Construction and Building Materials, 187, 1113 (2018).

[30]Cho B, Choi H., Construction and Building Materials, 123, 436 (2016).

[31]Zhang J W, He W D, Ni W, Hu W, Chen J., Chemical Engineering Transactions, 51, 1039 (2016).

[32]Li D X, Fu X H, Wu X Q., Cement and Concrete research, 27(7), 983 (1997).

[33]Mason B., Journal of Iron and Steel Institute, 11, 69 (1994).

[34]Li B X, Chen M Y, Wang W, Zhu Z G., Journal of Building Materials, 17(2), 206 (2014).

[35]Cui X W, Ni W., Revista de la Facultad de Ingeniería, 31(7), 172 (2016).

[36]Cui X W, Ni W, Ren C., Chinese Journal of Materials Research, 31(9), 687 (2017). 